\title{
Potentiation of carbon tetrachloride hepatotoxicity by pentosan polysulfate in rats
}

M.C.A. Zim ${ }^{1}$,

T.R. Silveira ${ }^{2}$,

G. Schwartsmann ${ }^{3}$,

T. Cerski ${ }^{4}$

and A. Motta ${ }^{5}$

\section{Correspondence \\ M.C.A. Zim \\ Rua 14 de Julho, 291/4 \\ 91340-430 Porto Alegre, RS \\ Brasil \\ Fax: +55-51-334-0146 \\ E-mail: zim@elonet.com.br}

Part of a Master's thesis presented by M.C.A. Zim to the Departamento de Pediatria, Universidade Federal do Rio Grande do Sul, Porto Alegre, RS, Brasil.

Received January 4, 2002 Accepted August 12, 2002
${ }^{1}$ Hospital da Criança Santo Antônio, Santa Casa de Misericórdia de Porto Alegre, Universidade Federal do Rio Grande do Sul, Porto Alegre, RS, Brasil

Departamentos de ${ }^{2}$ Pediatria, ${ }^{3}$ Clínica Médica, and ${ }^{4}$ Patologia, Faculdade de Medicina, Universidade Federal do Rio Grande do Sul, Porto Alegre, RS, Brasil

${ }^{5}$ Faculdade de Veterinária, Universidade Federal do Rio Grande do Sul, Porto Alegre, RS, Brasil (in memoriam)

\section{Abstract}

Few data are available in the literature regarding the effect of pentosan polysulfate (PPS) on normal and fibrotic rat livers. In addition, the combination of PPS and carbon tetrachloride $\left(\mathrm{CCl}_{4}\right)$ has not been studied so far. The objective of this study was to assess the effect of PPS on rat livers treated or not with $\mathrm{CCl}_{4}$ for the induction of liver fibrosis. The study consisted of four stages: 1) hepatic fibrosis induction with $\mathrm{CCl}_{4}(\mathrm{~N}=36$ rats $)$; 2) evaluation of the effect of PPS on $\mathrm{CCl}_{4}$ induced hepatic fibrosis ( $\mathrm{N}=36$ rats); 3 ) evaluation of the effect of higher doses of PPS in combination with $\mathrm{CCl}_{4}(\mathrm{~N}=50$ rats); 4) evaluation of the presence of an enzymatic inductor effect by PPS $(\mathrm{N}=18$ rats) using the sodium pentobarbital test which indirectly evaluates hepatic microsomal enzyme activity in vivo. Adult (60 to 70 days) male Wistar rats weighing 180 to $220 \mathrm{~g}$ were used. All animals receiving $0.5 \mathrm{ml} 8 \% \mathrm{CCl}_{4}(\mathrm{~N}=36)$ developed hepatic fibrosis, and after 8 weeks they also developed cirrhosis. No delay or prevention of hepatic fibrosis was observed with the administration of $5 \mathrm{mg} / \mathrm{kg}$ PPS $(\mathrm{N}=8)$ and $1 \mathrm{mg} / \mathrm{kg}$ PPS $(\mathrm{N}=8) 1 \mathrm{~h}$ after the administration of $\mathrm{CCl}_{4}$, but the increased hepatotoxicity resulting from the combination of the two substances caused massive hepatic necrosis in most rats $(\mathrm{N}=45)$. PPS (40 mg/kg) alone caused hepatic congestion only after 8 weeks, but massive hepatic necrosis was again observed in association with $0.5 \mathrm{ml} \mathrm{CCl}_{4}$ after 1 to 4 weeks of treatment. Unexpectedly, sleeping time increased with time of PPS administration (1, 2, or 3 weeks). This suggests that PPS does not function as an activator of the hepatic microsomal enzymatic system. Further studies are necessary in order to clarify the unexpected increase in hepatotoxicity caused by the combination of $\mathrm{CCl}_{4}$ and high doses of PPS, which results in massive hepatic necrosis.
Key words

- Cirrhosis

- Fibrogenesis

- Hepatic necrosis

- Pentosan polysulfate

- Carbon tetrachloride 


\section{Introduction}

Carbon tetrachloride $\left(\mathrm{CCl}_{4}\right)$ is a potent hepatotoxic agent often used to induce hepatic lesions, as well as to evaluate the effects of drugs on the liver. Short-term administration of $\mathrm{CCl}_{4}$ causes acute hepatocellular injury with centrolobular necrosis and steatosis. Chronic administration may lead to cirrhosis (liver fibrosis) (1). The time to onset of experimental cirrhosis depends on species, route of administration, dose, interval between doses, and use of enzymatic inducers.

The development of liver fibrosis involves expression of cellular receptors for several growth factors that stimulate the proliferation of activated lipocytes and the synthesis of extracellular matrix (2-4). Regression of hepatic fibrosis has been reported in a number of studies, but as yet no substance has been shown to be safe and effective enough for the treatment of hepatic fibrosis $(5,6)$. The modulation of cytokines may be a promising approach due to their action on fibrogenesis and on lipocyte proliferation $(4,5,7)$.

Pentosan polysulfate (PPS) is a semisynthetic heparinoid polysaccharide that has been used as an antithrombotic agent in the prophylaxis of deep venous thrombosis and postoperative thromboembolism (8). Some studies also suggest its usefulness as an antitumoral agent $(9,10)$. It is well known that PPS has an inhibitory effect on fibroblast growth factor, and thus this cytokine, in principle, could be used to treat hepatic fibrosis. However, there are few data concerning the effects of PPS on the liver. Therefore, the objective of the present study was to investigate the effect of PPS on the liver of rats submitted to fibrosis induction with $\mathrm{CCl}_{4}$.

\section{Material and Methods}

\section{Animals}

This study was approved by the Research
Ethics Committee of Hospital de Clínicas de Porto Alegre, Brazil, and followed international guidelines for the care and use of laboratory animals (11).

A total of 140 male Wistar rats were used (age range: 60-70 days, weight range: 180$220 \mathrm{~g}$ ). The animals were obtained from the Institute for Biosciences, Universidade Federal do Rio Grande do Sul, and were kept under a 12-h light/dark cycle, with rat chow and water available ad libitum. The animals were weighed every 7 days for weight control and for the adjustment of the $\mathrm{CCl}_{4}$ and PPS doses.

\section{$\mathrm{CCl}_{4}$-induced hepatic fibrosis}

Hepatic fibrosis was induced with $\mathrm{CCl}_{4}$. Intragastric gavage administration of $8 \% \mathrm{CCl}_{4}$ in mineral oil was performed once a week. The dose of $\mathrm{CCl}_{4}$ followed the scheme proposed by Rosa et al. (12): an initial dose of $0.5 \mathrm{ml}$ followed by doses calculated on the basis of 5\% variations in weight: every time a $5 \%$ increase in weight was observed, the dose was increased by $0.25 \mathrm{ml}$; on the other hand, when a weight loss of 5\% was observed, the dose was reduced by $0.25 \mathrm{ml}$. $\mathrm{CCl}_{4}$ was administered for a minimum of 4 and a maximum of 12 weeks.

\section{Pentosan polysulfate}

PPS was obtained as a donation from Bene-Chemie, Munich, Germany (Fibrezyn or Pentosan Polysulfate SP54). One daily dose was applied subcutaneously for 8 to 10 weeks (13). The doses used were 40, 25, 10 , 5 , and $1 \mathrm{mg} / \mathrm{kg}$ alone or in combination with $\mathrm{CCl}_{4}$.

\section{Study stages}

Stage 1: Induction of hepatic fibrosis with $\mathrm{CCl}_{4}$. Hepatic alterations resulting from $\mathrm{CCl}_{4}$ administration were evaluated in 36 animals divided into six groups respectively 
sacrificed at weeks $4,5,6,8,10$, and 12 of $\mathrm{CCl}_{4}$ treatment.

Stage 2: Evaluation of the effect of PPS on $\mathrm{CCl}_{4}$-induced hepatic fibrosis. Thirty-six animals were divided into six groups. One group received $40 \mathrm{mg} / \mathrm{kg}$ PPS alone $(\mathrm{N}=3)$, and the other groups received $40(\mathrm{~N}=3), 25$ $(\mathrm{N}=7), 10(\mathrm{~N}=7), 5(\mathrm{~N}=8)$, and $1(\mathrm{~N}=8)$ $\mathrm{mg} / \mathrm{kg}$ PPS in combination with $\mathrm{CCl}_{4}$. Treatment duration was planned for 8 to 10 weeks, based on previous studies $(1,14)$ and on the results from stage 1 , which showed that cirrhosis was induced after 8 weeks.

Upon completion of stage 2, an unexpected increase in $\mathrm{CCl}_{4}$ hepatotoxicity was detected in rats receiving 40,25 and $10 \mathrm{mg} / \mathrm{kg}$ PPS. Therefore, two further stages were planned:

Stage 3: Histological assessment of the liver after administration of combined PPS and $\mathrm{CCl}_{4}$. Five groups of 10 animals each received the following treatments: PPS 40 $\mathrm{mg} / \mathrm{kg}$ only, $\mathrm{CCl}_{4}$ plus PPS at 40,25 , and 10 $\mathrm{mg} / \mathrm{kg}$, and saline solution.

Stage 4: Sodium pentobarbital test (15) to evaluate the presence of an enzymatic inductor effect by PPS. The duration of the pentobarbital hypnotic effect, correlated with its metabolism, was used to evaluate in vivo the enzymatic activity of hepatic microsomal oxidases (16). The time of hypnosis is defined as the period during which the rat remains in dorsal decubitus before returning to ventral decubitus (righting reflex). In this stage, nine animals were divided into three groups of three, receiving $40 \mathrm{mg} / \mathrm{kg}$ PPS once daily for 1 , 2 , or 3 weeks. In addition, nine animals were divided into three control groups of three animals each. The control animals received subcutaneous saline solution only.

\section{Sacrifice}

All animals were sacrificed by ether anesthesia. Laparotomy was performed along the midline and the liver was removed for histological analysis.

\section{Histological analysis}

Liver samples were fixed in $4 \%$ formalin and stained with hematoxylin and eosin. Picrosirius was used to assess fibrosis. The material was examined under a light microscope by a pathologist who was not aware of the treatment groups.

The alterations assessed were necrosis, steatosis, blood congestion, fibrosis, and cirrhosis. The classification of hepatic fibrosis was based on a semiquantitative method described by Ruwart et al. (17) and modified by Zhao et al. (18): 0 - normal or inconclusive increase of fibrous tissue; 1 - increased fibrous tissue without septa; 2 - increased fibrous tissue with incomplete septa; 3 increased fibrous tissue with complete, thin septa dividing the parenchyma into separate fragments; 4 - definite increase of fibrous tissue with thick septum formation and evidence of cirrhosis.

We did not carry out histological analyses of other organs.

\section{Statistical analysis}

The chi-square or Fisher exact test was used to compare histological alterations and degree of fibrosis, and to analyze the frequency of massive hepatic necrosis and cirrhosis. Analysis of variance (two-factor ANOVA) and the Student-Newman-Keuls test were used to evaluate the results of the pentobarbital test (sleeping time). In stage 2, survival curves were plotted for animals receiving PPS and $\mathrm{CCl}_{4}$.

\section{Results}

\section{Induction of hepatic fibrosis with $\mathrm{CCl}_{4}$}

All 36 animals receiving $\mathrm{CCl}_{4}$ developed hepatic fibrosis. The type of fibrosis observed in the six experimental groups (sacrificed at $4,5,6,8,10$ or 12 weeks) was similar, suggesting a homogeneous response 
to $\mathrm{CCl}_{4}$. The degree of fibrosis increased gradually. Fibrosis degrees 1 and 2 were more frequent before week $6(\mathrm{P}<0.0003)$, degree 3 was observed at weeks 5 and 6 , and degree 4 was more frequent after week 6 $(\mathrm{P}<0.005)$. Cirrhosis was induced after a mean period of 8 weeks.

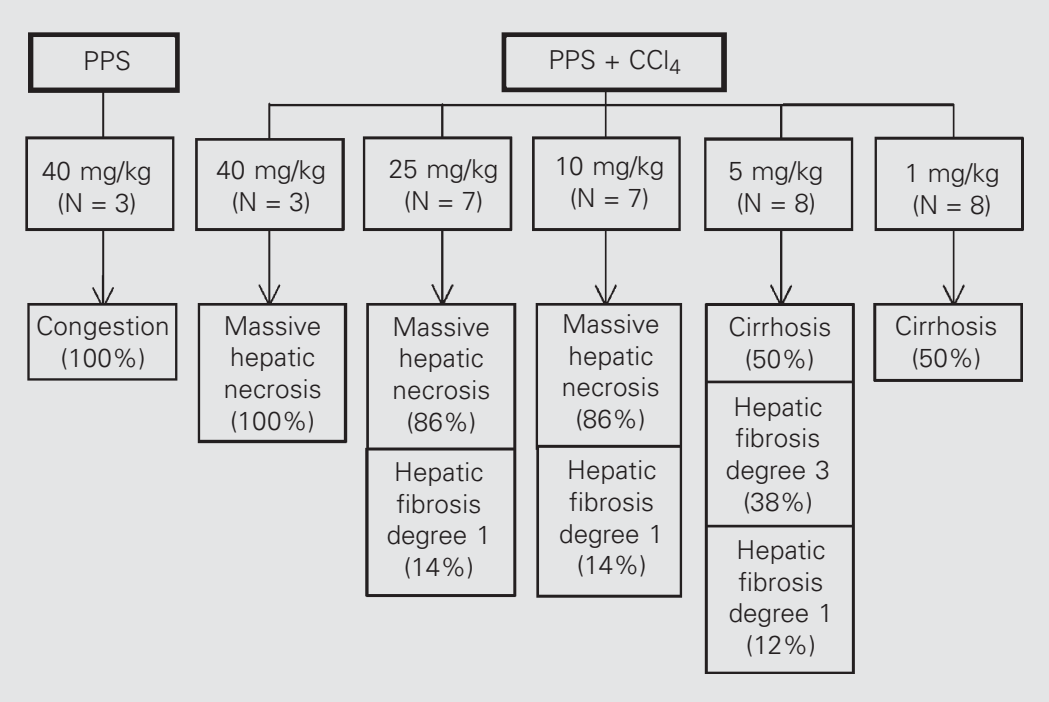

Figure 1. Histological alterations in animals treated with pentosan polysulfate (PPS) with or without $\mathrm{CCl}_{4}$. PPS $40 \mathrm{mg} / \mathrm{kg}\left(\mathrm{N}=3,8\right.$ weeks of treatment); PPS $40 \mathrm{mg} / \mathrm{kg}+\mathrm{CCl}_{4}(\mathrm{~N}=3,1$ to 3 weeks of treatment); PPS $25 \mathrm{mg} / \mathrm{kg}+\mathrm{CCl}_{4}$ ( $\mathrm{N}=7,2$ to 4 weeks of treatment); PPS 10 $\mathrm{mg} / \mathrm{kg}+\mathrm{CCl}_{4}\left(\mathrm{~N}=7,3\right.$ to 6 weeks of treatment); PPS $5 \mathrm{mg} / \mathrm{kg}+\mathrm{CCl}_{4}(\mathrm{~N}=8,7$ to 10 weeks of treatment); PPS $1 \mathrm{mg} / \mathrm{kg}+\mathrm{CCl}_{4}$ ( $\mathrm{N}=8,8$ to 10 weeks of treatment).

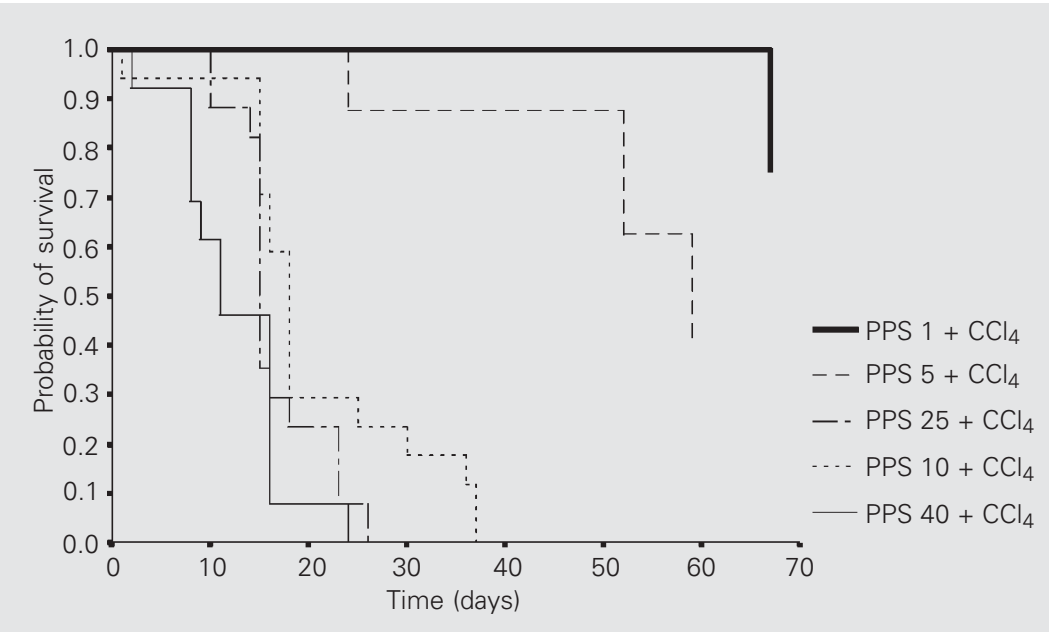

Figure 2. Kaplan-Meier survival analysis in animals treated with $\mathrm{CCl}_{4}$ and pentosan polysulfate (PPS). The probability of survival decreased with time of treatment in animals receiving 10,25 and $40 \mathrm{mg} / \mathrm{kg}$ PPS. PPS $1 \mathrm{mg} / \mathrm{kg}+\mathrm{CCl}_{4}$ ( $\mathrm{N}=8,8$ to 10 weeks of treatment); PPS $5 \mathrm{mg} / \mathrm{kg}+\mathrm{CCl}_{4}$ ( $\mathrm{N}=8,7$ to 10 weeks of treatment); PPS $10 \mathrm{mg} / \mathrm{kg}+\mathrm{CCl}_{4}$ ( $\mathrm{N}=7,3$ to 6 weeks of treatment); PPS $25 \mathrm{mg} / \mathrm{kg}+\mathrm{CCl}_{4}(\mathrm{~N}=7,2$ to 4 weeks of treatment); PPS 40 $\mathrm{mg} / \mathrm{kg}+\mathrm{CCl}_{4}(\mathrm{~N}=3,1$ to 3 weeks of treatment).

\section{Evaluation of the effect of PPS on $\mathrm{CCl}_{4}$-induced hepatic fibrosis}

Figure 1 shows the histological alterations observed in animals treated with PPS with or without $\mathrm{CCl}_{4}$. Animals receiving only PPS at $40 \mathrm{mg} / \mathrm{kg}$ showed congestion associated with dilatation of centrolobular veins and sinusoids in zone 3, presence of blood cells, and mild atrophy of liver cords. On the other hand, animals receiving $\mathrm{CCl}_{4}$ and 1 and $5 \mathrm{mg} / \mathrm{kg}$ PPS presented ascites. These doses of PPS were associated with development of cirrhosis. Kaplan-Meier analysis revealed that when $\mathrm{CCl}_{4}$ was combined with PPS doses higher than 5 $\mathrm{mg} / \mathrm{kg}$, the probability of survival decreased with time of treatment (Figure 2).

We unexpectedly observed that PPS at the doses of 40,25 , and $10 \mathrm{mg} / \mathrm{kg}$ in combination with $\mathrm{CCl}_{4}$ resulted in massive hepatic necrosis in 100,86 , and $86 \%$ of the rats, respectively. The presence of massive necrosis was significantly higher $(\mathrm{P}<0.001)$ in these groups when compared with the group receiving PPS alone and with the groups receiving 1 and $5 \mathrm{mg} / \mathrm{kg}$ PPS in combination with $\mathrm{CCl}_{4}$.

\section{Histological assessment of the liver after combined administration of PPS and $\mathrm{CCl}_{4}$}

The finding of massive hepatic necrosis in rats receiving high doses of PPS in combination with $\mathrm{CCl}_{4}$ was unexpected. In a subsequent stage of the study, again, all animals died spontaneously due to massive hepatic necrosis starting at treatment week 1 . Sixty percent of the deaths occurred at week 3 . The control group was sacrificed at week 10 and did not show histological hepatic alterations. Figure 3 shows the microscopic aspect of the liver of rats who died of massive hepatic necrosis and Figure 4 shows the microscopic aspect of the liver of rats with micronodular cirrhosis.

Table 1 summarizes the histological findings for the liver of rats receiving different doses of PPS in stages 2 and 3. 
Pentobarbital test

The sleeping time of animals pretreated with saline solution ranged from 50 to 83 min. Means were $66.6 \mathrm{~min}$ for the group sacrificed after 1 week of PPS administration, $67.3 \mathrm{~min}$ for the 2-week group, and 64.6 min for the 3-week group.

In rats receiving PPS, sleeping time ranged from 68 to $232 \mathrm{~min}$. Means were $93.3 \mathrm{~min}$
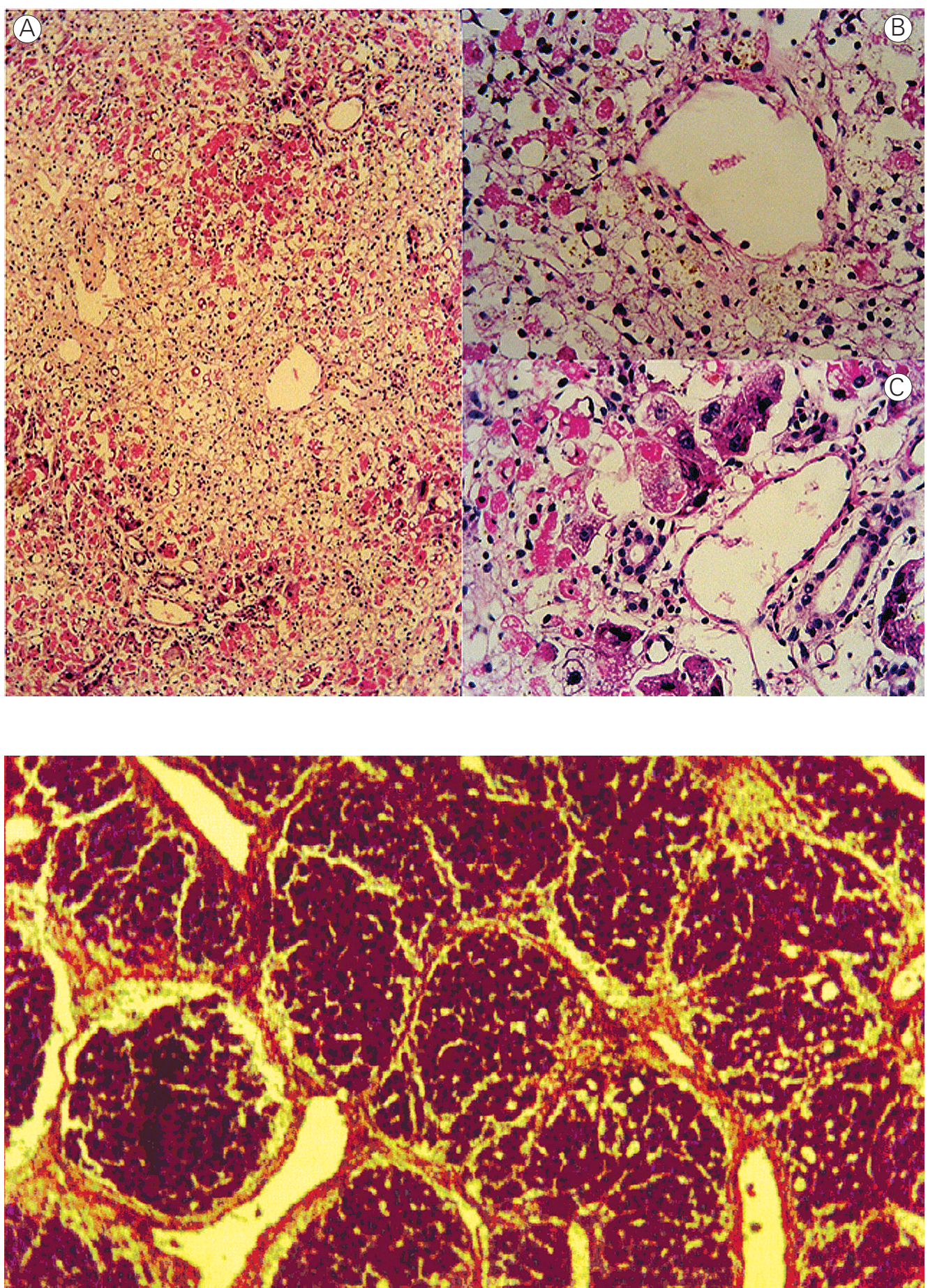

Figure 3. Photomicrograph of hepatic fragment: $A$, massive hepatic necrosis (HE, 100X); $B$, portal area (HE, 400X); $C$, centrolobular vein (HE, 400X). Administration of PPS $40 \mathrm{mg} / \mathrm{kg}+$ $\mathrm{CCl}_{4}$. Death occurred in the second week of treatment.
Figure 4. Photomicrograph of hepatic fragment: micronodula cirrhosis (HE/Sirius red, 100X). Administration of PPS $5 \mathrm{mg} / \mathrm{kg}$ $+\mathrm{CCl}_{4}$ for 8 weeks. 
for the 1-week group, $124.6 \mathrm{~min}$ for the 2week group, and 207.3 min for the 3-week group. Analysis of variance (two-factor ANOVA) was used to evaluate the treatment-week interaction, followed by comparison of means using the Student-NewmanKeuls test of multiple comparisons between means. The group pretreated with PPS for 3 weeks showed a significantly longer sleeping time than all other groups. The group pretreated with PPS for 2 weeks showed a longer sleeping time than controls, but not significantly different from the 1-week PPS group. The results of PPS for the 1-week group were not different from those of control rats. Table 2 shows the comparison between these means.

Table 1. Histological hepatic alterations observed with different doses of pentosan polysulfate (PPS).

\begin{tabular}{ccccc}
\hline Histological alteration & PPS at 40,25, and & PPS $5 \mathrm{mg} / \mathrm{kg}$ & $\mathrm{PPS} 1 \mathrm{mg} / \mathrm{kg}$ & $\mathrm{PPS}$ \\
& $10 \mathrm{mg} / \mathrm{kg}+\mathrm{CCl}_{4}$ & $+\mathrm{CCl}_{4}$ & $+\mathrm{CCl}_{4}$ & $40 \mathrm{mg} / \mathrm{kg}$ \\
$(\mathrm{N}=47)$ & $(\mathrm{N}=8)$ & $(\mathrm{N}=8)$ & $(\mathrm{N}=13)$
\end{tabular}

Focal centrolobular necrosis Massive hepatic necrosis

Fibrosis

Cirrhosis

Steatosis

Centrolobular congestion

PPS $40 \mathrm{mg} / \mathrm{kg}+\mathrm{CCl}_{4}$ (1 to 4 weeks of treatment); PPS $25 \mathrm{mg} / \mathrm{kg}+\mathrm{CCl}_{4}$ (2 to 4 weeks of treatment); PPS $10 \mathrm{mg} / \mathrm{kg}+\mathrm{CCl}_{4}$ ( 1 to 6 weeks of treatment); PPS $5 \mathrm{mg} / \mathrm{kg}+\mathrm{CCl}_{4}$ (7 to 10 weeks of treatment); PPS $1 \mathrm{mg} / \mathrm{kg}+\mathrm{CCl}_{4}$ (8 to 10 weeks of treatment); PPS $40 \mathrm{mg} / \mathrm{kg}$ alone (8 weeks of treatment).

Table 2. Effect of pentosan polysulfate (PPS) administration on phenobarbital-induced sleeping time.

\begin{tabular}{lcc}
\hline Week of trial & $40 \mathrm{mg} / \mathrm{kg}$ PPS $(\mathrm{min})$ & Saline solution (min) \\
\hline 1 & $93.3^{\mathrm{b}, \mathrm{c}}$ & $66.6^{\mathrm{c}}$ \\
2 & $124.6^{\mathrm{b}}$ & $67.3^{\mathrm{c}}$ \\
3 & $207.3^{\mathrm{a}}$ & $64.6^{\mathrm{c}}$
\end{tabular}

Rats received $40 \mathrm{mg} / \mathrm{kg}$ PPS daily for 1, 2 and 3 weeks; $\mathrm{N}=3$ animals in each group. Identical letters denote identical means $(P=0.05$, Student-Newman-Keuls test). Comparison between the two groups (PPS and saline): $F=54.580, P<0.001$. Comparison between the 3 weeks in the PPS group: $F=10.606, P=0.002$. Comparison among the six groups: $F=11.515, P=0.002$.

\section{Discussion}

The present study was designed to assess the impact of PPS administration on $\mathrm{CCl}_{4}$ induced cirrhosis in rats. As expected, we observed different types of hepatic lesions depending on the duration of $\mathrm{CCl}_{4}$ administration. From week 4 on, fibrosis was observed in $80 \%$ of the animals. Half the rats presented cirrhosis at week 6 , and from week 8 on, all showed this alteration. These results are similar to those reported by others $(1,14$, 19,20).

Reports on PPS toxicity are few $(8,9,21$, $22)$. In the present study, except for a moderate degree of hepatic congestion and the appearance of hematomas at the application site, we did not observe any major alterations induced by high doses of PPS (40 $\mathrm{mg} / \mathrm{kg}$ or higher) without $\mathrm{CCl}_{4}$. All animals receiving only PPS were well at the time of sacrifice, a fact that excludes the possibility that the congestion observed consisted of an agonal change induced by PPS.

Cytokine modulation has been thought to be a promising approach to the treatment of hepatic fibrosis due to its action on lipocyte proliferation and on fibrogenesis $(3,4,23)$. We initially expected that PPS binding to the growth factor would prevent degradation of this factor, thus promoting fibrosis $(24,25)$, similarly to what occurs in inflammatory processes when the growth factor binds to the proteoglycans of the extracellular matrix. However, contrary to our expectations, we did not observe any antifibrogenic effect of PPS on $\mathrm{CCl}_{4}$-induced lesions. Similarly, Ferreira et al. (26) assessed the effect of PPS on lung fibrosis induced by intratracheal bleomycin in rats. These authors used 25 $\mathrm{mg} / \mathrm{kg}$ PPS and did not observe inhibition of lung fibrosis.

The presence of massive hepatic necrosis was an unexpected result of the combination of $\mathrm{CCl}_{4}$ and high doses of PPS. Initially, we thought that this effect might have resulted from the increased bioactivation of $\mathrm{CCl}_{4}$ 
caused by the effect of PPS on the cytochrome P450 system (27). This possibility was evaluated by the sodium pentobarbital test (sleeping time). Sodium pentobarbital is a barbiturate whose action is short and whose hypnotic effect is linked to its metabolism rather than to its distribution. As reported above, the rats that were pretreated with PPS did not show the expected reduction in sleeping time. Surprisingly, the opposite effect was observed, i.e., the animals presented increased sleeping time associated with the duration of PPS administration (the longer the period of PPS administration, the longer the sleeping time). These data suggest that PPS interfered with the metabolism of this hypnotic agent, and that the drug did not activate the hepatic microsomal enzymatic system.

The increased hepatotoxicity of $\mathrm{CCl}_{4}$ in association with PPS may have been due to other mechanisms, such as increased lipid peroxidation (28) and decreased concentrations of glutathione and alpha-tocopherol (29). A recent study performed by Mizuoka et al. (30) with colchicine and $\mathrm{CCl}_{4}$ showed a hepatoprotective effect when colchicine was administered $18 \mathrm{~h}$ before $\mathrm{CCl}_{4}$ treatment, and an increase in hepatic injury when colchicine was administered $2 \mathrm{~h}$ before $\mathrm{CCl}_{4}$ treatment. This hepatoprotective effect was related to the decreased hepatic content of cytochrome $\mathrm{P} 450$, and the acceleration of hepatic necrosis was ascribed to increased membrane lipid peroxidation (30). Another explanation for our observation may be an interference of $\mathrm{CCl}_{4}$ with the half-life of PPS.

Our results indicate the need for greater care in using heparinoid drugs such as PPS in patients with liver disease. Further studies are necessary to clarify the unexpected presence of massive hepatic necrosis with the use of PPS plus $\mathrm{CCl}_{4}$.

In summary, no delay or prevention of hepatic fibrosis was observed with the use of PPS in rats. The use of PPS resulted in moderate hepatic congestion. Massive hepatic necrosis occurred as a result of the combined use of PPS and $\mathrm{CCl}_{4}$. This finding has not been previously reported in the literature, and its mechanism was not explained by stimulation of the microsomal enzymatic system, as shown by the pentobarbital test.

\section{Acknowledgments}

We thank the Graduate Research Group of Hospital de Clínicas de Porto Alegre for providing editorial support.

\section{References}

1. Jimenez W, Claria J, Arroyo V \& Rodés J (1992). Carbon tetrachloride induced cirrhosis in rats: a useful tool for investigating the pathogenesis of ascites in chronic liver disease. Journal of Gastroenterology and Hepatology, 7: 90-97.

2. Gressner AM (1995). Cytokines and cellular crosstalk involved in the activation of fat-storing cells. Journal of Hepatology, 22 (Suppl 2): 28-36.

3. Dooley S, Delvoux B, Lahme B, Mangasser-Stephank K \& Gressner AM (2000). Modulation of transforming growth factor beta response and signaling during transdifferentiation of rat hepatic stellate cells to myofibroblasts. Hepatology, 31: 1094-1106.
4. Andus $T$ \& Holstege A (1995). Role of cytokines in hepatic and hepatobiliary diseases. In: Aggarwal BB \& Puri RK (Editors), Human Cytokines: Their Role in Disease and Therapy. 1st edn. Blackwell Sciences, Cambridge, MA, USA, 625-640.

5. Friedman SL (1993). The cellular basis of hepatic fibrosis. New England Journal of Medicine, 328: 1828-1835.

6. Schuppan D, Strobel D \& Hahn EG (1998). Hepatic fibrosis - therapeutic strategies. Digestion, 59: 385-390.

7. Strobel D \& Hahn EG (1997). Pathogenesis of liver fibrogenesis. Digestion, 58 (Suppl): 37-38.

8. Maffrand JP, Herbert JM, Bernat A, Defreyn G, Delebassee D, Savi P, Pinot JJ
\& Sampol J (1991). Experimental and clinical pharmacology of pentosan polysulfate. Seminars in Thrombosis and Haemostasis, 17 (Suppl 2): 186-197.

9. Zugmaier G, Lippman ME \& Wellstein A (1992). Inhibition by pentosan polysulfate (PPS) of heparin-binding growth factors released from cells and blockage by PPS of tumor growth in animals. Journal of the National Cancer Institute, 84: 716-724.

10. Schwartsmann G, Sprinz E, Kalakun L, Yamagushi N, Sander E, Grivicich I, Koya $R$ \& Mans AR (1996). Phase II study of pentosan polysulfate (PPS) in patients with Aids-related Kaposi's sarcoma. Tumori, 82: 360-363.

11. Goldim JR (1995). Pesquisa em Saúde e 
Direitos dos Animais. Hospital de Clínicas de Porto Alegre, Porto Alegre, RS, Brazil.

12. Rosa $H$, Parise ER, Parnhos FRL, Braga AL, Freitas ASO, Hidalgo NA \& Mor MBL (1991). Controlled production of cirrhosis in the rat liver. Arquivos de Gastroenterologia, 28: 39-43.

13. Kiesel J, Harbauer G, Wenzel E, Pindur G \& Bohnerth $S$ (1991). Comparison of the effects of sodium pentosan polysulfate and unfractionated heparin on venous thrombosis; an experimental study in rats. Thrombosis Research, 64: 301-308.

14. Tsukamoto H, Matsuoka M \& French SW (1990). Experimental models of hepatic fibrosis: a review. Seminars in Liver Disease, 10: $56-65$

15. Conney AH, Davison C, Gastel R \& Burns JJ (1960). Adaptive increases in drugmetabolizing enzymes induced by phenobarbital and other drugs. Journal of Pharmacology and Experimental Therapeutics, 130: 1-8.

16. Trivedi P \& Mowat AP (1983). Carbon tetrachloride-induced hepatic fibrosis and cirrhosis in the developing rat: an experimental model of cirrhosis in childhood. British Journal of Experimental Pathology, 64: 25-33.

17. Ruwart MJ, Wilkinson KF, Rush BD, Vidmar TJ, Peters KM, Henley KS, Appelman HD, Kim KY, Schuppan D \& Hahn EG (1989). The integrated value of serum procollagen III peptide over time predicts hepatic hydroxyproline content and stainable collagen in a model of dietary cirrhosis in the rat. Hepatology, 10: 801-806.
18. Zhao J, You D, Chen X \& Wu J (1992) Monitoring of serum markers for fibrosis during $\mathrm{CCl}_{4}$-induced liver damage. Effects of anti-fibrotic agents. Journal of Hepatology, 16: 282-289.

19. Mion F, Géloën A, Agosto E \& Minaire $Y$ (1996). Carbon tetrachloride-induced cirrhosis in rats: influence of the acute effects of the toxin on glucose metabolism. Hepatology, 23: 582-588.

20. Hayasaka A, Koch J, Schuppan D, Maddrey WC \& Hahn EG (1991). The serum concentrations of the aminoterminal propeptide of procollagen type III and the hepatic content of mRNA for the alpha 1 chain of procollagen type III in carbon tetrachloride-induced rat liver fibrogenesis. Journal of Hepatology, 13: 328-338.

21. Wellstein A \& Lippman ME (1991). Fibroblast growth factors and breast cancer. In: Broder S (Editor), Molecular Foundations of Oncology. Williams and Wilkins, Baltimore, MD, USA, 403-418.

22. Odling B, Dencker L \& Tengblad A (1987). Preferential localization of $3 \mathrm{H}$-pentosan polysulfate to the urinary tract in rats. Pharmacology and Toxicology, 61: 162166.

23. Wasser $\mathrm{S}$, Ho JMS, Ang HK \& Tan CEL (1998). Salvia miltiorrhiza reduces experimentally-induced hepatic fibrosis in rats. Journal of Hepatology, 29: 760-771.

24. Flaumenhaft R, Moscatelli D, Saksela O \& Rifkin DB (1990). The role of extracellular matrix in the action of basic fibroblast growth factor: matrix as a source of growth factor for long term stimulation of plasminogen activator production and syn- thesis. Journal of Cellular Physiology, 140: 75-81.

25. Saksela O, Moscatelli D, Sommer A \& Rifkin DB (1988). Endothelial cell-derived heparin sulfate binds basic fibroblast growth factor and protects it from proteolytic degradation. Journal of Cell Biology, 107: 743-751.

26. Ferreira AF, Brandão SLB, Prolla JC, Silva VD, Meurer L, Edelweiss MI, Schwartsmann G \& Rigatto M (1999). Fibrose pulmonar induzida por bleomicina intratraqueal em ratos Wistar. Descrição do modelo experimental de síndrome de angústia respiratória do adulto e uso do pentosan polissulfato. Arquivos Médicos, 2: 23-33.

27. Liv J, Sendelbach LE, Parkinson A \& Klaassen CD (2000). Endotoxin pretreatment protects against the hepatotoxicity of acetaminophen and carbon tetrachloride: role of cytochrome P450 suppression. Toxicology, 147: 167-176.

28. EISissi AED, Ernest DL \& Sipes GI (1993). Vitamin A potentiation of carbon tetrachloride hepatotoxicity: enhanced lipid peroxidation without enhanced biotransformation. Toxicology and Applied Pharmacology, 119: 289-294.

29. Losser MR \& Payen D (1996). Mechanisms of liver damage. Seminars in Liver Disease, 16: 357-367.

30. Mizuoka H, Shikata N, Yang J, Takasu M, Inoue K \& Tsubura A (1999). Biphasic effect of colchicine on acute liver injury induced by carbon tetrachloride or by dimethylnitrosamine in mice. Journal of Hepatology, 31: 825-833. 